\title{
Research on Promoting Night Tourism and Night Economic Development in Guilin City
}

\author{
Gong Chenli ${ }^{1}$ \\ ${ }^{1}$ College of Tourism and Landscape Architecture, Guilin University of Technology, Guilin 541000,China
}

\begin{abstract}
In the historical period when China's economy is committed to high-quality development, the nighttime economy has attracted much attention because of its huge consumption potential. With the rapid warming of tourism fever, night tourism is not only an important part of urban tourism development, but also injects vitality into the economic development of a city. Taking Guilin as an example, this paper makes an indepth analysis of the potential of developing night tourism in Guilin, and puts forward suggestions from two aspects of macro-control environment and product development, so as to promote the vigorous development of night tourism and night economy in Guilin.
\end{abstract}

\section{Introduction}

Urban night tourism refers to all kinds of activities carried out by tourists and urban residents for the purpose of tourism and leisure from sunset to sunrise the next day $^{[1]}$. The extension of night tourism mainly includes night sightseeing tour, night festival tour, night cultural and artistic leisure tour, night cultural performance experience tour, block night tour and scenic spot night tour ${ }^{[2]}$.According to statistics, night consumption in Beijing, Shanghai, Shenzhen, Guangzhou and other cities has accounted for $50 \%$ of all-day consumption, and the proportion is rising. Compared with daytime tourism products, night tourism products can stimulate tourists' consumption psychology in sensory enjoyment, aesthetic state and experience mode ${ }^{[3]}$.Night tourism can prolong the leisure time and enrich the forms of night tourism products, which is an important driving force for Guilin's economic and social prosperity and progress.

\section{Guilin's potential to develop night tourism}

\subsection{Have a good tourism market}

According to the statistics of domestic and foreign tourism industry, although the scale of night tourism is smaller than that of day tourism, people's consumption intention and impulse are stronger than that of day tourism, so night tourism is an important way to extend the tourism service chain. In 2019, Guilin achieved a total tourism consumption of 139.117 billion yuan, a year-on-year increase of $43.225 \%$. From the perspective of the domestic tourism consumption structure of the whole city, the top three are: catering, shopping and sightseeing in scenic spots, accounting for $19.17 \%, 18.27 \%$ and $14.98 \%$ respectively. According to the stay time of tourists, $40.57 \%$ of tourists stayed for 3-4 days in 2019. The total number of tourists and overnight visitors in Guilin is huge. In 2019, the city received 106 million domestic tourists, a year-onyear increase of $33.28 \%$. Among them, there are 41.8105 million overnight tourists, accounting for $39.29 \%$ of the total number of domestic tourists. It can be seen that night tourism has great consumption potential and is an important part of promoting Guilin's economic development at night.

Table1. Statistical table of the number of tourists received in

\begin{tabular}{|c|c|c|c|c|c|}
\hline & $\mathbf{2 0 1 6}$ & $\mathbf{2 0 1 7}$ & $\mathbf{2 0 1 8}$ & $\mathbf{2 0 1 9}$ & $\mathbf{2 0 2 0}$ \\
\hline $\begin{array}{c}\text { Total number of } \\
\text { tourists } \\
\text { (ten thousand) }\end{array}$ & 5386 & 8233 & 10915 & 13834 & 10241 \\
\hline $\begin{array}{c}\text { Year-on-year } \\
\text { growth rate }\end{array}$ & $21.3 \%$ & $53.5 \%$ & $32.6 \%$ & $26.7 \%$ & $-26.0 \%$ \\
\hline $\begin{array}{c}\text { Inbound } \\
\text { overnight } \\
\text { tourists (ten } \\
\text { thousand) }\end{array}$ & 233.3 & 248.9 & 274.7 & 314.6 & 9.8 \\
\hline $\begin{array}{c}\text { Year-on-year } \\
\text { growth rate }\end{array}$ & $7.8 \%$ & $6.7 \%$ & $10.4 \%$ & $14.5 \%$ & $-96.9 \%$ \\
\hline
\end{tabular}

Data source: Guilin Bureau of Statistics, official wbsite of Guilin Culture, Radio, Television and Tourism Bureau.

\subsection{Guilin is rich in tourism resources}

Guilin is rich in natural scenery, social resources and industrial resources. In recent years, water system green spaces, parks and squares, commercial and gourmet blocks, performing arts venues and scenic spots have also developed continuously, forming new tourism resources such as leisure and recreation belts, health and wellness, ancient city charm and shopping consumption, and the combination of red patriotism, green ecology and urban

${ }^{1}$ Corresponding author:1432479539@qq.com 
leisure as the development trend. East-West Lane, Yangshuo West Street, Longji Terrace, Zijiang Denggu Scenic Spot, Impression Liu Sanjie Performing Arts, Guilin Ancient Love Performing Arts and other scenic spots are widely welcomed by domestic and foreign tourists, and become the most important punch-in tourist attractions for domestic and foreign tourists.

Table2. Statistical table of tourist reception of the most popular scenic spots in Guilin in 2019.

\begin{tabular}{|c|c|}
\hline The scenic spot & $\begin{array}{c}\text { Tourist reception } \\
\text { (ten thousand) }\end{array}$ \\
\hline Dongxi lane & 829.89 \\
\hline Yangshuo West Street & 489.14 \\
\hline Longji terraced fields scenic spot & 397.72 \\
\hline Zijiang Light Valley Scenic Spot & 211.61 \\
\hline Impression Liu Sanjie performing arts & 159.42 \\
\hline Xing'an Lingqu scenic spot & 90.02 \\
\hline Guilin Eternal Love Performing Arts & 85.20 \\
\hline
\end{tabular}

\subsection{Sound industrial system}

Guilin has a complete range of products and services for night travelers, covering food, shopping, tourism and entertainment. There are 61 star-rated hotels in the city, including 20 four-star and five-star hotels; There are more than 240 cruise ships in Lijiang River and Two Rivers and Four Lakes; There are 52 tourist bus service companies and 3,619 tourist service vehicles; There are 333 travel agencies in the city, with about 12,400 licensed tour guides. The language of tour guides involves 14 foreign languages and local dialects such as English, Japanese, French, Spanish and German. According to the following table, tourists in 2019 can be divided into star-rated accommodation facilities, non-star accommodation facilities and staying with relatives and friends. It can be seen that the reception of non-star accommodation has increased rapidly, which is 17.23 percentage points higher than that of star-rated accommodation, indicating that nonstar accommodation facilities including characteristic homestays in Guilin are widely welcomed and sought after.

Table3. Statistical table of overnight tourists classified by accommodation method in 2019.

\begin{tabular}{|c|c|c|c|}
\hline & $\begin{array}{c}\text { Number of } \\
\text { people } \\
\text { (ten thousand } \\
\text { people) }\end{array}$ & $\begin{array}{c}\text { Year-on- } \\
\text { year } \\
\text { increase }\end{array}$ & $\begin{array}{c}\text { Percentage of } \\
\text { total overnight } \\
\text { visitors in China }\end{array}$ \\
\hline $\begin{array}{c}\text { Star } \\
\text { accommodation } \\
\text { facilities }\end{array}$ & 243.16 & $-12.33 \%$ & $5.82 \%$ \\
\hline $\begin{array}{c}\text { Non-star } \\
\text { accommodation } \\
\text { facilities }\end{array}$ & 3605.86 & $37.53 \%$ & $5.82 \%$ \\
\hline $\begin{array}{c}\text { Relatives or } \\
\text { friends home }\end{array}$ & 332.03 & $6.93 \%$ & $7.94 \%$ \\
\hline
\end{tabular}

\subsection{Advanced night tourism development experience}

Among Guilin night tour products, cultural experience and performing arts night tour products are well-known in the whole country and the world. Impression Liu Sanjie, which was performed in 2004, is the first real-life performance in China and the first large-scale real-life performance in the world. Since 2004, more than 7,200 performances have been performed, with an audience of 19 million people. Impression Liu Sanjie changed the tourism pattern of Guilin and lit up the night economy of Yangshuo. Guilin has earnestly summed up the night tourism experience of Yangshuo and continued to build a number of classic night tourism projects integrating natural landscape, history and culture and leisure tourism, such as Zhengyang East-West Lane, Xiaoyao Building, which combine the scenery of Lijiang River with history and culture, and started the tourism development mode of combining day tourism with night tourism. The current situation of night tourism in Guilin has provided advanced experience for further development.

\section{Suggestions on the development of night tourism in Guilin}

\subsection{Macro-environmental aspects}

\subsubsection{Carry out scientific planning}

To develop night tourism, we should pay attention to overall planning and rational distribution. Although Guilin's large-scale live performances of night tourism products are famous all over the world, compared with Shanghai, Chongqing, Beijing, Wuhan and other cities, Guilin's night tourism has much room for development and progress ${ }^{[4]}$. The development of night tourism products should combine the demand of tourism market, consider the changes of future demand, develop marketable night tourism products for tourists with different needs, and clarify the positioning, objectives, layout and measures of Guilin night tourism development ${ }^{[5]}$.The introduction of guiding opinions to promote the development of night economy has created a good policy and industrial development environment for the development of night tourism.

\subsubsection{Improve public services}

Urban public service systems, such as transportation, safety, information and consultation, are all indispensable and inseparable in night tourism operation. Government management departments should invest more resources and provide comprehensive basic service guarantee, so that tourists can experience the full enthusiasm of Guilin people and merchants can feel the high-quality business environment. For example, London has set up a night working committee composed of various policy experts and industry leaders to help the mayor draw up night economic development goals, while Amsterdam has created the concept of night mayor to supervise night economic activities, and establish a communication mechanism to balance the needs of stakeholders.

\subsubsection{Build a special intellectual support platform}

The development of night tour products spans multiple departments, organizations, institutions and disciplines, and needs the participation of multiple subjects. It is 
composed of a series of cultural policies, artistic and cultural activities, cultural and creative platforms, financing exchanges and urban construction behaviors. We should create an open platform for communication and exchange for a large number of entrepreneurs, cultural, artistic, tourism, planning, creative talents, social activists, managers, students, establish corresponding mechanisms, create an innovative cultural atmosphere, and provide intellectual support and innovative environment for the innovation of night tour products and the renewal and development of urban leisure industry in Guilin.

\subsubsection{Increase tourism publicity}

Strong publicity can improve the popularity of night tourism in Guilin in a short period of time and realize the goal of night tourism development in Guilin. In the publicity, we should bring the old with the new, make use of the well-known products to create brand effect, bring forth the old into the market in a timely manner, make extensive use of media marketing, and add some night tourism scenes in Guilin promotional films and promotional posters, so that viewers can have a preliminary affection and yearning for Guilin night tourism. In addition, the use of festival marketing, and strive to Guilin's night tourism to the world.

\section{2 product development}

\subsubsection{Clever use of old village resources}

Many old villages in Guilin have been demolished during urban renewal, and most of the new buildings are residential quarters, forming a repetitive and uniform urban landscape. Transform the old village into a leisure area, rectify the spatial features, and concentrate on planting leisure formats, such as various bars, cafes, restaurants, book bars, academies, art academies, concert halls, cultural experience halls, recreation and entertainment, art galleries, cultural and creative retail stores, multi-functional plazas, to form an industrial cluster, and use innovative leisure formats to activate night consumption, realize the gathering of business flows and people flows, and update and increase the land function of the old village area.

\subsubsection{Pay attention to lighting effect}

In the landscape of night tourism products, lighting is the basic means of night tourism. On the basis of the development of existing night tourism, large-scale night programs such as lighting festival and light show are carried out. The lighting festival is based on local culture, using waterfalls, fountains and other water resources in the scenic spot as water curtains, and performing a threedimensional water show with the help of light and shadow technology. By means of situation simulation, amusement, sightseeing, theme and amorous feelings experience,4D experience, relying on the tourism resources of the scenic spot, combined with lighting effects, it creates a multi- dimensional lighting exhibition, focusing on immersive interactive play, bringing tourists into an immersive night tourism space, and creating a never-night tourism city with Guilin characteristics.

\subsubsection{Determine the prominent themes}

The development of night tourism needs a theme orientation to extract its essence. At present, the night tourism products represented by Suzhou and Wuxi have achieved great success. In order to develop night tourism in Guilin, it is necessary to establish prominent themes and make scientific positioning according to the situation of night tourism market and the basis of Guilin tourism resources.

\subsubsection{Enrich the product form at night}

Guilin should dig deep into the historical culture and the cultural connotation and value of the city itself under the guiding concept of global night tour, and integrate it with modern new formats to develop various forms of cultural night tour products, such as cultural customs and characteristic commercial streets, historical and cultural corridors and other historical blocks, and natural areas such as Lijiang River water system, forming powerful and attractive core products of urban night tour such as blocks, parks, festivals, landscapes and performing arts, such as Zhengyang East-West Lane.

\section{Conclusion}

The night-time economy plays an important role in urban revival, economic growth and cultural creation. Developing night-time tourism in Guilin can not only solve the problem of retaining tourists, but also promote the economic development of Guilin. At present, there are still some problems in the planning, management and product innovation of night tourism in Guilin. According to the analysis of the potentiality of night tourism in Guilin, this paper concludes that Guilin has the advantages to develop night tourism. The development of Guilin night economy has a long way to go. In the future, the government, scenic spots, tourists and other social forces need to participate together to promote the vigorous development of Guilin night tourism and promote the prosperity and progress of Guilin's economy and society.

\section{References}

1. Wen tong. study on urban night tourism products [J]. urban problems, 2007,(08): 42-45.

2. Wang lucang, Yan cuixia, Li Wei. study on the temporal and spatial characteristics of tourism flow based on Sina Weibo big data-taking Lanzhou city as an example [J]. journal of tourism, 2017. 32(05): 94105.

3. Zhang Yuwei. Analysis of industrial development certification of night tourism [J]. China Commerce and Trade, 2011,(14): 168-169. 
4. Liu Yi, Teng Mengqin. Study on the network structure of night tourism flow based on tourism digital footprint-taking Guangzhou as an example [J] 51(02): 279-286.

5. Liu Li, Qi Wei, Jiao Lingling. A research profile of urban tourism: a review of domestic and foreign research on urban tourism products $[\mathrm{J}]$. Resource Development and Market, 2012, 28(12): 1139-1142. 